\title{
DETERMINANTES DA ESTRUTURA DE CAPITAL DE EMPRESAS BRASILEIRAS: UMA ANÁLISE EMPÍRICA DAS TEORIAS DE PECKING ORDER E TRADE-OFF NO PERÍODO DE 2005 E 2014
}

\section{RESUMO}

O presente estudo investiga os determinantes da estrutura de capital, utilizando a técnica de regressão múltipla de dados, para uma amostra de 723 empresas, de diversos setores da economia brasileira, no período de 2005 e 2014 , a fim de determinar a importância relativa dos fatores específicos da empresa. A teoria do pecking order oferece a existência de uma hierarquia no uso de fontes de recursos, enquanto a teoria de trade-off considera a existência de uma estrutura meta de capital que seria perseguida pela empresa. Foram utilizadas doze variáveis contábeis, nas quais cinco foram dependentes (relacionadas à endividamentos) e mais sete como variáveis independentes (explicativas dos determinantes da estrutura de capital). Foram elas: a) endividamentos: Endividamento Total; Endividamento de Curto Prazo; Endividamento de Longo Prazo; Endividamento Financeiro Oneroso de Curto Prazo; e, Endividamento Financeiro Oneroso de Longo Prazo; b) Determinantes da Estrutura de Capital: Liquidez Corrente; Tangibilidade; Retorno dos Ativos; Retorno aos Investidores; Nível de Pagamento do Imposto de Renda; Crescimento das Vendas; e, Crescimento dos Ativos. Os principais resultados deste estudo como contribuição foram os seguintes: a) relações positivas em tangibilidade dos ativos e negativa para os retornos dos ativos; b) a liquidez corrente está relacionada negativamente com os indicadores de endividamento; c) o retorno aos investidores não foi possível confirmar sua relação com os indicadores de endividamento; d) crescimento dos ativos é relacionada positivamente com o endividamento a curto prazo e relacionada negativamente com os endividamentos de curto e longo prazos financeiros onerosos; e) o crescimento das vendas é relacionada negativamente com os indicadores de endividamento; f) o nível de pagamento de imposto de renda apresentou uma relação positiva junto ao endividamento de curto prazo, não sendo possível comparála com outros níveis de endividamento.

Palavras chaves: Teoria de Trade Off; Teoria de Pecking Order; Endividamento; Determinantes da Estrutura de Capital; Análise de Regressão Múltipla Linear.

\section{DETERMINANTS OF THE CAPITAL STRUCTURE OF BRAZILIAN COMPANIES: AN EMPIRICAL ANALYSIS OF PECKING ORDER AND TRADE-OFF THEORIES IN 2005 AND 2014}

\begin{abstract}
This study investigates the determinants of capital structure, using multiple regression technique data for a sample of 723 companies from various sectors of the Brazilian economy between 2005 and 2014 in order to determine the relative importance of the factors specific company. The theory of pecking order provides the existence of a hierarchy in the use of funding sources, while the trade-off theory considers the existence of a target capital structure that would be pursued by the company. Twelve financial variables were used in which five were dependent (related to indebtedness) and seven independent variables (explanatory of the determinants of capital structure). These were: a) indebtedness: Total Indebtedness; Short-term debt; Long-term debt; Costly Financial debt Short-term; and Financial Debt Costly Longterm; b) Determinants of Capital Structure: Current liquidity; Tangibility; Return on assets; Return to Investors; Payment level of income tax; Sales Growth; and Asset Growth. The main results of this study as a contribution were: a) positive relationships in asset tangibility and negative for asset returns; b) the current ratio is negatively related with the debt indicators; c) the return to investors could not confirm their relationship with debt indicators; d) growth of assets is positively related to short-term debt and negatively related to the indebtedness of short and long onerous financial terms; e) sales growth is negatively related to the debt indicators; f) the level of income tax payment showed a positive relationship with the short-term debt, it is not possible to compare it to other levels of indebtedness.
\end{abstract}

Keywords: Theory of Trade Off. Pecking Order theory. Debt. Determinants of Capital Structure. Multiple Linear Regression Analysis. 


\section{DETERMINANTES DE LA ESTRUCTURA DEL CAPITAL EN LAS EMPRESAS BRASILEÑAS: UN ANÁLISIS EMPÍRICO A PARTIR DE LAS TEORÍAS DE PECKING ORDER Y LA TEORÍA TRADE-OFF POR LOS AÑOS 2005 Y 2014}

\section{RESUMEN}

El presente estudio investiga los determinantes de la estructura del capital, utilizando la técnica de análisis de regresión múltiple, con una muestra de 723 empresas de diversos sectores de la economía brasileña, en el período de 2005 y 2014 , a fin de determinar la importancia relativa de los factores específicos de la empresa. La teoría del pecking order ofrece la existencia de una jerarquía en el uso de fuentes de recursos, mientras que la teoría de trade-off considera la existencia de una meta-estructura de capital que sería perseguida por la empresa. Se utilizaron doce variables contables, en las cuales: a) cinco fueron dependientes relacionadas con los endeudamientos: endeudamiento total, endeudamiento de corto plazo, endeudamiento a largo plazo, endeudamiento financiero oneroso de corto plazo, y el endeudamiento financiero a lo largo de largo plazo; y b) siete variables más explicativas de los determinantes de la estructura de capital como lo son liquidez Corriente, tangibilidad, Retorno de los activos, Retorno a los inversores, Nivel de Pago del Impuesto sobre la Renta, crecimiento de las ventas y el crecimiento de los activos. Los principales resultados de este estudio como contribución, fueron los siguientes: a) relaciones positivas en tangibilidad de los activos y negativa para el retorno de los activos; b) la liquidez corriente está relacionada negativamente con los indicadores de endeudamiento; c) para el retorno a los inversores no fue posible confirmar su relación con los indicadores de endeudamiento; d) el crecimiento de los activos se relaciona positivamente con el endeudamiento a corto plazo y se relaciona negativamente con los endeudamientos financieros onerosos a corto y largo plazo; e) el crecimiento de las ventas se relaciona negativamente con los indicadores de endeudamiento; f) el nivel de pago del impuesto sobre la renta presentó una relación positiva con el endeudamiento a corto plazo, no siendo posible compararla con otros niveles de endeudamiento.

Palabras clave: Teoría de Trade Off. Teoría de Pecking Order. Endeudamiento. Determinantes de la estructura de capital. Análisis de Regresión Múltiple Lineal

\footnotetext{
${ }^{1}$ Doutorando em Administração de Negócios pelo Instituto Universitario ESEADE (Escuela Superior de Economía y Administración de Empresas), Argentina. Professor da Universidade Federal de São Paulo - UNIFESP. Brasil. E-mail: marcelo@mrhenriqueconsult.com.br

${ }^{2}$ Doutorando em Administração pela Universidade Presbiteriana Mackenzie. Professor da Universidade Federal de São Paulo - UNIFESP. Brasil. E-mail: prof_sandrobraz@hotmail.com

${ }^{3}$ Mestre em Administração de Empresas pelo Centro Universitário das Faculdades Metropolitanas Unidas - FMU. Brasil. E-mail: wendell_soares@ig.com.br

${ }^{4}$ Doutorando em Administração pelo Centro Universitário das Faculdades de Engenharia Industrial - FEI. Brasil. Email: sergioroberto@auditaconsultoria.com.br
} 


\section{INTRODUÇÃO}

A contemporânea teoria de estrutura de capital surgiu com o trabalho de Modigliani e Miller (1958), em que apontaram na direção de que em certas condições, a forma de financiamento das empresas é irrelevante. Os determinantes da estrutura de capital não estão restritos apenas aos fatores específicos das firmas. Como fatores específicos das firmas, incluemse, entre, outros, nível de tangibilidade, tamanho, rentabilidade, risco, oportunidades de crescimento, nível de imposto de renda, benefícios ficais. Cada um desses fatores pode ser considerado um determinante da estrutura de capital, porém seu comportamento pode variar de acordo com o referencial teórico abordado.

O questionamento clássico sobre estrutura de capital e qual a relação entre capital próprio e capital de terceiros que poderá maximizar o valor da empresa. Mencionando de outra forma, há um quociente ótimo entre capital de terceiros e capital próprio capaz de minimizar o custo de capital da empresa e, portanto, maximizar o valor da empresa? Dentre outros questionamentos em finanças, esse, também, e marcado por diversas respostas divergentes, de modo que não há como responder a essa pergunta de forma única e objetiva. (Bastos \& Nakamura, 2009).

A forma de como os gestores combinam as fontes de financiamento é uma decisão importante não só no contexto financeiro da firma, mas no estratégico também é considerado. A estrutura de capital trata da forma pela qual as firmas utilizam as fontes de origem, próprios e de terceiros, para aplicar em ativos (assets) e atividades que as demandam. A escolha da melhor combinação das origens de recursos da estrutura de capital ainda é um tema recorrente em finanças há décadas. Estudos sobre os efeitos da alavancagem financeira nas decisões de melhor alocação de recursos nas organizações, historicamente, contribuíram para o avanço das discussões na academia. (Camilo, Xavier, De Mello \& Marcon, 2010)

Dentre os assuntos abordados pela teoria de finanças corporativas, a parte relativa a estrutura de capital e uma das mais complexas e polemicas. Não obstante haver uma série de pesquisas teóricas e empíricas, tal assunto não possui uma resposta pronta e unânime sobre qual é a melhor ou mais adequada estrutura de capital para uma organização (Myers, 1984; Bradley, Jarrell \& Kim, 1984; Titman \& Wessel, 1988; Rajan \& Zingales, 1995; Shyam-Sunder \& Myers, 1999; Hovakimian, Opler \& Titman, 2001).

Ainda indagações relacionadas à escolha de financiamentos - débitos versus capital próprio - têm ganhado importância na pesquisa em estratégia gerencial. Num curto espaço de tempo houve um aumento significante na atenção dedicada pela literatura de estratégia gerencial a aspectos financeiros (Kochhar, 1997).
Desde o artigo de Modigliani e Miller (1958), pesquisadores analisam os fatores que afetam a estrutura de capital das empresas (Myers, 1984; Titman \& Wessels, 1988). A estrutura de capital é irrelevante para a concepção de valor da empresa e, portanto, não deveria existir uma preferência por determinado tipo de estrutura de capital (Modigliani \& Miller, 1958). Porém, no mundo real, cada empresa pode optar por um grau diferente de alavancagem. (Choi, Saito \& Silva, 2015).

No Brasil, diversos trabalhos teórico-empíricos foram realizados com o objetivo de elucidar o assunto estrutura de capital, tais como: Eid Jr. (1996); Kayo e Famá (1997); Perobelli e Famá (2003); Nakamura, Martin e Kimura (2004); Procianoy e Schnorrenberger (2004); Prates e Leal (2005); Bastos e Nakamura (2009); e, Raifur e Sousa (2011). Já os estudos para verificar a influência da estrutura de capital na performance foram conduzidos por Famá e Melher (1999), Pereira (2000) e Mesquita e Lara (2003), embora, divergem em seus resultados.

A partir deste cenário, a questão problema é: "Quais são os determinantes da estrutura de capital de empresas listadas na bolsa de valores brasileira, analisando nas perspectivas empíricas das teorias de pecking order e trade-off no período entre 2005 e 2014?".

O presente estudo analisa os determinantes da estrutura de capital de empresas abertas na Bolsa de Valores de São Paulo, atualmente chamada de B3 Brasil, Bolsa Balcão, considerando os fatores específicos da empresa. Desse modo, aspectos institucionais ou econômicos não avaliados, limitando as análises, apenas, aos fatores específicos da empresa.

Para um entendimento mais abrangente do assunto foram escolhidos doze indicadores, com o objetivo de aprofundar a análise dos determinantes da estrutura de capital. O estudo compreende o período entre 2005 e 2014, à luz de duas teorias sobre estrutura de capital: a) Teoria do Trade off; b) Teoria do Pecking Order. No entanto, nesta pesquisa, o tratamento estatístico será de análise de regressão múltipla linear, utilizada em cinco modelos a serem propostos em seções subsequentes.

De forma geral, portanto, os índices de endividamento das empresas de países em desenvolvimento das empresas de países em desenvolvimento parecem ser afetados pelas mesmas variáveis que impactam no endividamento de empresas de países desenvolvidos. (Bastos \& Nakamura, 2009)

Perobelli e Famá (2003) apontam que a teoria de pecking order parece ser a mais robusta para explicar o grau de endividamento das empresas latino americanas, tal como observado em países desenvolvidos. 


\section{REVISÃO DE LITERATURA}

\subsection{Teoria do Trade Off (TOT)}

A teoria do Trade-off (TOT) está alicerçada nas economias fiscais relacionadas ao uso de dívidas e aos custos de falência esperados. Foi a partir da combinação de economias fiscais decorrentes do uso de dívidas e custos de falência esperados decorrentes do excesso de endividamento, que se estabeleceu o que veio a ser chamada de teoria do Trade-off. (Nakamura, Martin \& Kayo, 2004; Nakamura et al, 2007). De acordo com tal teoria, dois fatores em particular influenciam as decisões de endividamento das empresas: a) por um lado as economias fiscais esperadas pelo uso crescente de dívida e b) os custos de falência esperados que se manifestam para níveis elevados de endividamento, a partir do qual se tornam maiores quanto mais endividada for a empresa.

Em anos recentes, diferentes argumentos teóricos têm sido agrupados, esquematicamente para estrutura de capital, as teorias que enfocam os diversos custos e benefícios associados ao endividamento, a exemplo dos custos esperados de falência, custos de agência das dívidas (relacionados aos conflitos de interesse entre credores e acionistas da empresa), benefícios fiscais decorrentes da dedutibilidade das despesas financeiras e o efeito disciplinador que o endividamento exerce sobre os gestores. A este conjunto de argumentos denominou-se abordagem do trade-off, a qual prevê que as empresas procurarão uma estrutura de financiamentos ótima, ponderando as vantagens e desvantagens do endividamento. (Silveira, Perobelli \& Barros, 2008).

Ainda Nakamura, Martin e Kayo (2004), a escolha da teoria de trade-off abrange dois fatores que atuam como forças contrárias:

(a) o efeito das economias fiscais, agindo no sentido de incentivar o uso de dívidas;

(b) o efeito dos custos de falência esperados, que surgem da maior propensão de uma empresa tornar-se inadimplente.

Apesar do robusto embasamento teórico, as pesquisas empíricas, de forma geral, divergem quanto aos determinantes da estrutura de capital à luz da teoria trade-off. As variáveis tamanho, tangibilidade e benefício fiscal devem ter uma relação positiva com o endividamento, ao passo que as variáveis "risco operacional" e "benefício fiscal" não relativo a dívidas devem estar, negativamente relacionadas com o grau de alavancagem financeira. Quanto ao benefício fiscal não relativo a dívidas, no Brasil existe a figura dos Juros Sobre Capital Próprio, que é dedutível para fins de cálculo de imposto de renda e, sendo assim, poderá influenciar para menos o grau de endividamento da empresa. (Bastos \& Nakamura, 2009).
Às vezes, as decisões sobre a estrutura de capital dependem da escolha do projeto, ou vice-versa, e naqueles casos, as decisões de investimento e de financiamento têm de ser consideradas em conjunto (Brealey, Myers \& Allen, 2010).

\subsection{Teoria de Pecking Order (POT)}

A teoria do pecking order (POT) surge com os trabalhos de Myers e Majluf (1984) e Myers (1984) que consideram a empresa como detentoras de ativos já estabelecidos/conquistados e oportunidades de crescimento, em que a estrutura de capital é função da mudança dos pesos relativos desses dois componentes que formam a empresa (origens e aplicações). A empresa deveria utilizar dívidas para financiar esses ativos estabelecidos e ações para financiar novas oportunidades de crescimento. (Bastos \& Nakamura, 2009)

A principal alternativa a esta abordagem é a teoria da pecking order (Myers, 1984; Myers \& Majluf, 1984), a qual sustenta que as empresas tenderão a seguir uma hierarquia de preferência por diferentes fontes de financiamento, em razão da assimetria informacional que existe entre os seus gestores e os investidores externos. Sob a pecking order não existirá nenhuma estrutura de capital ideal a ser perseguida pela empresa. (Silveira, Perobelli \& Barros, 2008).

Para Myers (1984), as empresas preferem os seguintes: a) recursos financeiros internos; b) ajustam suas políticas de dividendos às seus investimentos oportunos; c) o fluxo de caixa gerado, formado por uma política de dividendos rígida, lucratividade variável e oportunidades de investimentos, podem ser maior ou menor que o gasto de capital; d) recursos financeiros externos com a emissão de títulos de dívida.

Campos e Nakamura (2015) afirmam que na teoria do pecking order (baseada em assimetria de informações) não há informação a um endividamento ótimo nível, mas o endividamento seria uma consequência entre as condições de assimetria de informação com a economia e o surgimento de bons projetos da empresa. Dentro desta teoria, fatores relacionados aos benefícios fiscais são considerados de segunda ordem.

Para essa corrente teórica, não há uma bem definida estrutura de capital. Não existe um nível ótimo de endividamento para a firma, ao contrário do que explana a teoria de trade-off.

Albuquerque (2013) basicamente a teoria da pecking order traça uma hierarquia de preferência de fontes de recursos pela empresa, mais especificamente, há uma preferência por recursos internos a externos, e quando esses últimos são requeridos, são priorizadas as dívidas e só depois se opta por emissões de ações.

Eid Jr (1996) em pesquisa com questionários aplicados em empresas brasileiras identificou que as companhias não se utilizavam de uma estrutura de 
capital meta/ideal, contrariando assim as ideias da teoria de estática de trade-off. Por outro lado o autor relatou um comportamento que refletia oportunismo dos gestores, os quais buscavam fontes de recursos priorizando aquelas de custo mais baixo. Em segundo lugar, o autor relatou uma preferência hierárquica de fontes de financiamento para empresas brasileiras, entretanto, diferentemente do preconizado pela teoria de pecking order, no Brasil a escala de preferência encontrada foi inicialmente os empréstimos bancários, em segundo lugar as ações ordinárias e só por último os lucros retidos (Albuquerque, 2013).

Shyam-Sunder e Myers (1999) e Myers (1999) testaram e compararam a teoria de pecking order com a teoria de trade-off, indicando que a primeira teoria prediz que mudanças do endividamento de cada ano dependem dos fluxos financeiros desse mesmo ano.

\subsection{Teste Conjunto de Teorías: Trade-Off x Pecking Order}

Duas corrente teóricas predominam nas explicações acerca das decisões sobre estrutura de capital: pecking order e trade-off. As explicações obtidas a partir delas são tidas como concorrentes e se divergem em vários pontos, como revisão nas seções anteriores.

Nas pesquisas de Fama e French (2002) confirmando as previsões compartilhadas pelos modelos de pecking order, empresas mais lucrativas e empresas com menos investimentos têm maiores pagamentos de dividendos. Confirmando o modelo de pecking order, mas contradizendo o modelo de tradeoff, as empresas mais lucrativas são menos alavancadas. As empresas com mais investimentos têm menos alavancagem do mercado, o que é consistente com o modelo de trade-off. As empresas com mais investimentos têm pagamentos de dividendos de longo prazo mais baixos, mas os dividendos não variam para acomodar a variação de curto prazo no investimento. Como prevê o modelo de pecking order, a variação de curto prazo em investimentos e ganhos é principalmente absorvida pela dívida.

Dada a ideia de que essas teorias são concorrentes, diversos trabalhos (Fama \& French, 2002, 2005; Shyam-Sunder \& Myers, 1999; Rajan \& Zingales (1995); Titman \& Wessels, 1998) se ocuparam de investigar as predições teóricas que se seguiram a partir delas. Destacam-se dois principais caminhos para estudar essas implicações. Sendo o primeiro, Shyam-Sunder \& Myers (1999) e Frank \& Goyal (2003) testaram as predições do modelo sobre a emissão de dívidas para cobrir déficits financeiros e pela segunda, Shyam-Sunder \& Myers (1999) Rajan \& Zingales (1995) e Hovakimian \& Li (2011) testaram as predições do modelo sobre estrutura alvao de capital.

Apesar de convergirem em alguns pontos, as teorias de trade-off e pecking order divergem em seus conceitos básicos. Uma gama de estudos foi realizada em meados de 2000, confrontando as duas teorias de estrutura de capitais (Fama \& French, 2002, 2003; Frank \& Goyal, 2003; Lemmon \& Zender, 2002; Sogorb-Mira \& López-Gracia, 2002). Como a teoria de pecking order estabelece que a subscrição de novas ações somente aconteça como último recurso e que a forma preferencial de financiamento do déficit financeiro se dá por meio de lucros retidos, há grande ponto de divergência entre as duas correntes. Para a teoria de trade-off, maiores lucros levam a maior endividamento, devido ao escudo fiscal proporcionado pelos juros. Isto é exatamente o oposto do que a teoria de pecking order sustenta; para ela maiores lucros levam à diminuição do endividamento, já que esses lucros, caso não sejam distribuídos, se tornam a melhor fonte de geração de recursos para cobrir o déficit financeiro da empresa. (Medeiros \& Daher; 2008).

Ainda o pagamento de dividendos pode ser outro motivo de divergência entre as duas teorias de estrutura de capital, dependendo do autor consultado. De acordo com Frank e Goyal (2003), para a teoria de trade-off, os dividendos também podem mitigar conflitos de agência como já vistos em sessões anteriores dessa pesquisa, estando, portanto, negativamente relacionados com o endividamento, já que diminui a necessidade de se usar dívidas para equacionar este conflito. A teoria de pecking order prevê uma relação direta entre endividamento e pagamento de dividendos, já que esses compõem o déficit financeiro da empresa. Fama e French (2002), afirmam que ambas as correntes consideram os dividendos como diretamente relacionados com o endividamento. O efeito dos juros é outro ponto de discordância. Para Frank e Goyal (2003), um aumento nas taxas de juros poderia levar à emissão de ações, já que juros maiores levam a empresa a atingir sua capacidade de endividamento de modo mais rápido. Assim, taxa de juros e endividamento seriam negativamente relacionados conforme evidenciados nos estudos anteriores. A relação entre endividamento e taxa de juros sob a teoria de trade-off se dá de forma indireta. Um aumento nas taxas de juros leva à diminuição no valor tanto das ações quanto das dívidas de longo prazo existentes. Ocorre que a diminuição no valor das ações é mais acentuada que das dívidas, levando ao aumento da proporção entre capital próprio e de terceiros. Ainda Frank e Goyal (2003), dentre as variáveis convencionais, a tangibilidade dos ativos é o fator mais importante para se optar por uma ou outra teoria. O motivo é que, ao contrário da lucratividade, que pode ser vista como proxy para oportunidades de crescimento (neste caso, o sinal poderia ser o mesmo para ambas as teorias: negativo), a tangibilidade dos ativos não oferece dupla interpretação e o sinal indicaria a superioridade explanatória de uma teoria sobre a outra. 


\section{PROCEDIMENTOS METODOLÓGICOS}

Este estudo tem por objetivo analisar a relação dos determinantes da estrutura de capital em empresas brasileiras com os indicadores de endividamento destas organizações e comparar os resultados desta relação com as teorias de pecking order e trade off.

A abordagem escolhida foi a quantitativa, utilizando-se da ferramenta econométrica de análise de regressão múltipla linear.

Antes disso, a metodologia utilizada como pesquisa fora a bibliográfica, documental, exploratória e descritiva. A pesquisa bibliográfica se caracteriza neste estudo como uma busca de embasamento teórico sob as principais leituras de cada assunto por meio de papers nacionais e internacionais. Quanto à pesquisa documental, a mesma fora realizada sob a extração dos dados de relatórios contábeis trimestrais de 723 empresas brasileiras listadas na CVM (Comissão de Valores Mobiliários) necessárias para este estudo do software Economática, entre o período de 2005 e 2014. À medida que os dados contábeis estavam em relatórios extra pesquisa do software MS Excel, acontecia a pesquisa exploratória, na qual, além desta atividade, foram realizadas atividades de cálculos para a maioria das variáveis. Como etapa final da metodologia utilizada, houve a pesquisa descritiva, ao qual cabe à descrição dos resultados da pesquisa e às considerações finais.

Para atingir o objetivo deste estudo, foram elaboradas algumas hipóteses a partir de estudos anteriores. Com isso, elabora-se uma construção de cada hipótese analisada neste estudo, propostas a seguir.

\subsection{Construção das Hipóteses}

Neste estudo, a formulação das hipóteses tomou por base o referencial teórico abordado na seção anterior, bem como estudos empíricos já realizados.

Booth et al (2001) e Bastos e Nakamura (2009), distinguir, empiricamente, as hipóteses entre as correntes teóricas tem se demonstrado uma tarefa difícil. Em muitas situações, o comportamento de uma variável ora pode ser explicado por uma teoria, ora por outra. Também, as correntes teóricas são conflitantes em buscar explicações para o comportamento de algumas variáveis.

Ainda Damodaran (2007), uma questão fundamental enfrentada ao realizar avaliações de empresas é a que nível de detalhamento será a avaliação: por um lado, acrescentar mais detalhes permitiria aos analistas a oportunidade de usar mais informações para realizar melhores previsões sobre cada item. Por outro lado, isso tornaria necessário gerar mais inputs, elevando o potencial de ocorrência de erros sobre cada um.

Em versões de Myers e Majluf (1984), Majluf (1984) e Nakamura et al (2007), a teoria de Pecking
Order propõe a utilização de endividamento para financiar ativos e ações em novas oportunidades de crescimento organizacional, na qual gestores acabam se pautando na hierarquia de recursos para realizarem apostas em oportunidades de crescimento. Nesta condição, é possível esperar que empresas mais lucrativas sejam menos endividadas. Ross (1977 apud Harris \& Haviv, 1991) defende que a relação entre rentabilidade e nível de endividamento seja positiva. Por outro lado, encontra-se na literatura o contrapondo de Brito, Corrar e Batistella (2007) que mencionam que a rentabilidade não é determinante para a estrutura de capital das organizações. Por meio desta discussão, constroem-se as seguintes hipóteses:

Hipótese 1: É negativa a relação entre retorno aos acionistas e indicadores de endividamento.

Hipótese 2: É negativa a relação entre retorno dos ativos e indicadores de endividamento.

Na formulação de outra hipótese, na visão de Myers e Majluf (1984), as empresas utilizam seus ativos como garantia de endividamento quando da necessidade de investimentos em oportunidades diversas que julga realizar. Assim, dificultam estratégias arriscadas utilizadas por acionistas de que tendem tirar riquezas de seus credores. Brito, Corrar e Batistella (2007) encontraram em pesquisa que existe uma relação negativa entre a composição dos ativos e o endividamento total. Portanto, nesta seara, é proposta a seguinte hipótese:

Hipótese 3: É positiva a relação entre crescimento dos ativos e os indicadores de endividamento.

Outro aspecto que foi interessante para construir mais uma hipótese partiram de estudos anteriores, onde as empresas com potencial de crescimento tendem a ter maior flexibilidade para investir, aumentando assim o endividamento das organizações, apontando, assim, uma relação negativa entre crescimento e endividamento. (Kayo \& Famá, 1997). Em outra concepção, Brito, Corrar e Batistella (2007) encontraram em seus estudos uma relação positiva do crescimento em relação a endividamento total e de longo prazo, não existindo relação com endividamento de curto prazo. Já Gomes e Leal (2001) apontam uma relação positiva entre o nível de crescimento e o endividamento das empresas, pois as empresas que mais crescem demandam de mais recursos para melhor gerir estas oportunidades, buscando fora da empresa tais recursos necessários para este propósito. Portanto, parte-se para a seguinte hipótese:

Hipótese 4: É negativa a relação entre crescimento de vendas e os indicadores de endividamento. 
Para Titman e Wessels (1988), os ativos tangíveis auxiliam as empresas a ampliar seus indicadores de endividamento, nas quais oferecem como garantias de pagamento. A lógica para este tipo de pensamento é de que a garantia em contrapartida da dívida minimiza a teoria de agência, problemas de conflitos, entre credores e acionistas/donos/gestores das organizações empresariais. Assim como apresentado por Myers e Majluf (1984), minimiza estratégias arriscadas dos proprietários com o interesse de apropriar-se de riqueza dos credores. Portanto, espera-se encontrar a seguinte hipótese:

Hipótese 5: É positiva a relação entre tangibilidade dos ativos e os indicadores de endividamento.

Bastos, Nakamura e Basso (2009) e Correa, Basso e Nakamura (2013) em seus estudos encontraram forte influência da variável que trata sobre o índice de liquidez corrente, cujo resultado foi de uma relação negativa entre liquidez e endividamento, confirmando hipótese à teoria do pecking order. Seguindo estas confirmações, a hipótese para este estudo é:

Hipótese 6: É negativa a relação entre liquidez corrente e os indicadores de endividamento.

A teoria de trade off apresenta uma relação positiva entre o nível de pagamento dos tributos e ao nível de endividamento. Correa, Basso e Nakamura
(2013) e Bastos, Nakamura e Basso (2009) encontraram evidências contrárias a este pressuposto da teoria, na qual o relacionamento entre o pagamento de imposto de renda é negativo aos endividamentos totais, a valor de mercado e ao financeiro oneroso de curto e longo prazos. Com isso, espera-se que a hipótese a ser apresentada seja:

Hipótese 7: É negativa a relação entre o nível de pagamento de imposto de renda e os indicadores de endividamento.

\subsection{Fontes e Coletas de Dados}

Os dados sobre os fatores específicos das empresas foram coletados diretamente do software Economática no primeiro trimestre de 2015, que fornece tanto dados contábeis como de mercado. Portanto, trata-se de dados secundários, compreendendo as variáveis econômico-financeiras de 723 empresas constantes na lista da CVM (Comissão de Valores Mobiliários).

Os dados trimestrais são provenientes dos Balanços Patrimoniais, Demonstrações do Resultado do Exercício e informações de mercado disponíveis no próprio banco de dados da Economática.

As variáveis que compõem o presente estudo estão demonstradas no Quadro 1 e no Quadro 2, expondo o nome das variáveis, suas siglas e fórmula de cálculo, apresentados a seguir:

\begin{tabular}{|l|c|c|}
\hline \multicolumn{1}{|c|}{ VARIÁ VEIS DE PESQUISA } & SIGLAS & FÓRMULA \\
\hline Endividamento Total & ET & $\frac{\text { Passivo Circulante + Passivo Não Circulante }}{\text { Ativo Total }}$ \\
\hline Endividamento de Curto Prazo a Valor & ECP & $\frac{\text { Passivo Circulante }}{\text { Ativo Total }}$ \\
\hline Endividamento de Longo Prazo a Valor & ELP & Ativo Não Circulante \\
\hline Endividamento Financeiro Oneroso de CP & ECPF & $\frac{\text { Debêntures e Financiamentos de Curto Prazo }}{\text { Ativo a Valor Contábil }}$ \\
\hline Endividamento Financeiro Oneroso de LP & ELPF & $\frac{\text { Debêntures e Financiamentos de Longo Prazo }}{\text { Ativo a Valor Contábil }}$ \\
\hline
\end{tabular}

Quadro 1 - Variáveis dependentes

Fonte: elaborada pelos autores.

As variáveis dependentes apresentadas no Quadro 1 representam os indicadores de endividamento que serão utilizadas nos modelos de regressão linear múltipla na execução deste estudo. Elas foram embasadas nas leituras de pesquisas anteriores.
Uma adaptação foi realizada nas contas e/ou grupos de contas contábeis devido a alterações na legislação contábil brasileira, sem alterar as ideias anteriormente propostas e que serviram de alicerce para esta pesquisa. 
Determinantes da Estrutura de Capital de Empresas Brasileiras: Uma Análise Empírica das Teorias de Pecking Order e Trade-Off no Período de 2005 e 2014

\begin{tabular}{|l|c|c|}
\hline \multicolumn{1}{|c|}{ VARIÁVEIS DE PESQUISA } & SIGLAS & FÓRMULA \\
\hline Liquidez Corrente & LC & Ativo Circulante / Passivo Circulante \\
\hline Tangibilidade & TANG & $\frac{\text { Ativo Imobilizado + Estoques }}{\text { Ativo Total }}$ \\
\hline Retorno aos Investidores & ROE & Lucro Líquido / Patrimônio Líquido \\
\hline Rentabilidade do Investimento & ROA & EBIT / Ativo Total \\
\hline Crescimento das Vendas & CRESCVD & $\frac{\text { Receita Líquida }_{\mathrm{t}}(-) \text { Receita Líquida }_{\mathrm{t}-1}}{\text { Receita Líquida }_{\mathrm{t}-1}}$ \\
\hline Crescimento dos Ativos & CRESCAT & $\frac{\text { Ativo Total }}{\mathrm{t}(-) \text { Ativo Total }_{\mathrm{t}-1}}$ \\
\hline Nível de Pagamento de Imposto de Renda & NPGIR & Valor de Imposto de Renda / EBIT \\
\hline
\end{tabular}

Quadro 2 - Variáveis independentes

Fonte: Elaborada pelos autores.

As variáveis independentes apresentadas no Quadro 2 representam os fatores determinantes para a estrutura de capital e que serão utilizadas nos modelos de regressão linear múltipla na execução deste estudo como variáveis explicativas. Elas foram embasadas nas leituras de pesquisas anteriores e terão a possibilidade, de apontar se existe alguma relação e qual representa se positiva ou se negativa.

\section{ANÁLISE DOS RESULTADOS}

Para atingir os objetivos iniciais foram realizadas algumas regressões, uma para cada índice de endividamento selecionado como variável dependente.

A validação dos pressupostos assumidos pelo modelo de regressão linear múltipla foram a partir dos seguintes testes:

a) multicolinearidade entre as variáveis independentes;

b) autocorrelação residual;

c) homocedasticidade; $\mathrm{e}$,

d) normalidade dos resíduos.
O tratamento dos dados foi realizado por meio do software SPSS versão 20 e o modelo demonstrado abaixo:

Endividamento $_{\mathrm{i}}=\alpha+\beta 1$ ET $_{\mathrm{i}}+\beta$ TANG $_{\mathrm{i}}+\beta 1$ ROA $i+\beta$ ROE $_{i}+\beta 1$ NPGIR $_{i}+\beta 1$ CRESCVD $_{i}+\beta 1$ CRESCAT $_{\mathrm{i}}+\mu_{\mathrm{i}}$

\subsection{Apresentação dos Resultados}

Um primeira análise a ser realizada para validação de pressupostos e aplicação da regressão múltipla é o teste de multicolinearidade entre as variáveis independentes propostas ao modelo.

Vasconcellos e Alves (2000) afirmam que uma maneira de diagnosticar a multicolinearidade consiste na análise dos coeficientes de correlação entre as variáveis independentes do modelo. Para tanto, à este estudo, a tabela 1 apresenta os resultados da matriz de correlação de Pearson, a seguir:

Tabela 1 - Correlação entre as variáveis independentes

\begin{tabular}{|c|c|c|c|c|c|c|c|}
\hline & $\mathrm{LC}$ & TANG & ROA & ROE & NPGIR & CRESCVD & CRESCAT \\
\hline$\overline{\mathrm{LC}}$ & 1,0000 & & & & & & \\
\hline TANG &,$- 198 * *$ & 1,0000 & & & & & \\
\hline ROA & ,034* & 0,0151 & 1,0000 & & & & \\
\hline ROE & 0,0153 & 0,0023 &, $045 * *$ & 1,0000 & & & \\
\hline NPGIR & 0,0037 & 0,0062 & 0,0090 & 0,0018 & 1,0000 & & \\
\hline CRESCVD & 0,0150 &,$- 102 * *$ & 0,0274 & 0,0087 & 0,0018 & 1,0000 & \\
\hline CRESCAT & 0,0129 &,$- 114 * *$ & 0,0140 & 0,0065 & 0,0032 &, $862 * *$ & 1,0000 \\
\hline
\end{tabular}

** Correlação é significante ao nível de $1 \%$, nas duas caudas

* Correlação é significante ao nível de 5\%, nas duas caudas

Fonte: Dados da pesquisa. 
Analisando os resultados da Tabela 1, percebese que os resultados indicam que não houve violação do pressuposto da inexistência de multicolinearidade entre as variáveis explicativas, nas quais não possuem alta correlação entre si.

As variáveis mais relacionadas foram CRESCVD e CRESCAT, respectivamente representando o Crescimento das Vendas e o
Crescimento do Ativo, apresentando um coeficiente de correlação positiva de 0,8618 .

A segunda tentativa de validar os dados às regressões propostas como modelo foi realizado ao pressuposto de autocorrelação residual, utilizando-se do teste de Durbin-Watson, haja vista que a amostra deste estudo é de 3.972 casos, superior a 50. Este teste é um dos mais utilizados. Vasconcellos e Alves (2000)

Tabela 2 - Teste de Durbin-Watson (autocorrelação residual)

\begin{tabular}{l|c|l|r|r}
\hline $\begin{array}{c}\text { Variáveis } \\
\text { Dependentes }\end{array}$ & Modelos & \multicolumn{1}{|c|}{ Variáveis Independentes que entraram no modelo } & $\begin{array}{c}\text { R2 } \\
\text { Ajustado }\end{array}$ & $\begin{array}{c}\text { Durbin- } \\
\text { Watson }\end{array}$ \\
\hline ET & 1 & (Constante), ROA & 0,0575 & 1,8584 \\
ECP & 6 & (Constant), ROA, LC, TANG, NPGIR, CRESCAT, CRESCVD & 0,1073 & 0,2926 \\
ELP & 3 & (Constant), LC, ROA, TANG & 0,0735 & 0,3126 \\
ECPF & 4 & (Constant), ROA, LC, TANG, CRESCAT & 0,1059 & 0,4512 \\
ELPF & 4 & (Constant), ROA, TANG, LC, CRESCAT & 0,0370 & 0,2778 \\
\hline
\end{tabular}

Fonte: Dados da pesquisa.

Os resultados apresentados por meio do teste de Durbin-Watson determinam que quanto mais próximos de 2 exista a ausência de autocorrelação significativa entre os resíduos, demonstrado na Figura 1.

Figura 1 - Autocorrelação residual

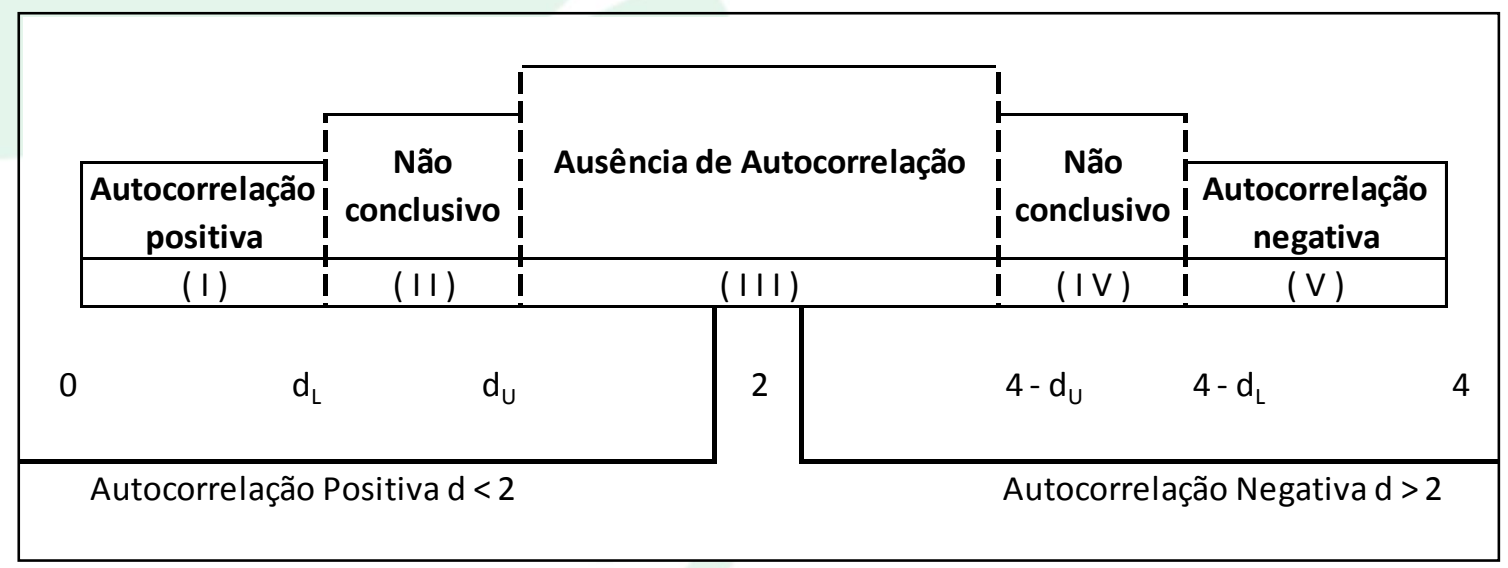

Fonte: Corrar, Paulo e Dias Filho (2007), adaptado.

Analisando os resultados deste estudo, percebese que o modelo de regressão na qual prevê como endividamento a variável ET (Endividamento Total) estar próximo de 2 , se encontrando na posição (III ausência de autocorrelação).

Esta afirmação é confirmada devido aos cálculos necessários para conhecer em que posição se encontra a autocorrelação residual, pois o teste de Durbin-Watson poderá possuir resultados que transitam entre 0 e 4, assim, como apresentado anteriormente, resultados próximos de 2 demonstrarem ausência de autocorrelação residual.

Para valores que atuem entre 2 e 4, é necessário aplicar o cálculo determinado pela Figura 1, na qual conhecerá em que posição do teste de Durbin-Watson se encontra a autocorrelação ou não do modelo.
Com isso, o Durbin-Watson possui dois valores críticos como divisor das posições: o valor crítico inferior, onde $d_{L}=1,797$; o valor crítico superior, onde $\mathrm{d}_{\mathrm{U}}=1,824$. Logo, para $\mathrm{d}_{\mathrm{L}}$ tem-se o seguinte: $4-\mathrm{d}_{\mathrm{L}}$, quer dizer, $4-1,797=2,176 \mathrm{e}$, para $\mathrm{d}_{\mathrm{U}}$ tem-se $\mathrm{o}$ seguinte: $4-\mathrm{d}_{\mathrm{U}}$, quer dizer, $4-1,824=2,203$. Assim sendo, o resultado da regressão múltipla para a variável ET se encontra entre 2,176 e 2,203 (1,8584) se encontrando na posição de ausência de correlação.

Para os demais modelos, conforme testes realizados Durbin-Watson se encontram na posição (I), na condição de autocorrelação positiva.

Tais resultados não são desconsiderados porque os demais testes, de homocedasticidade e de normalidade dos resíduos foram satisfatórios, demonstrando que os dados são homogêneos e menos 
Determinantes da Estrutura de Capital de Empresas Brasileiras: Uma Análise Empírica das Teorias de Pecking Order e Trade-Off no Período de 2005 e 2014

dispersos e, que as distribuições dos resíduos das regressões analisadas seguem uma distribuição de probabilidade aproximadamente normal.

Com o término dos testes e com resultados satisfatórios foi aplicada a regressão múltipla linear para cada uma das variáveis dependentes selecionadas.

A Tabela 3 apresenta à identificação de cada variável dependente e respectivos modelos, além dos resultados da soma dos quadrados, os graus de liberdade, as médias dos quadrados, as estatísticas $\mathrm{F}$ e os testes de significância, que avaliam a significância estatística de cada parâmetro e os coeficientes de determinação ajustados ( $\mathrm{R}^{2}$ ajustado), que indicam o poder explicativo da regressão, conforme Tabela 2.

Tabela 3 - Resultados dos modelos de regressão

\begin{tabular}{|c|c|c|c|c|c|c|c|}
\hline $\begin{array}{c}\text { Variáveis } \\
\text { Dependentes }\end{array}$ & & Modelos & $\begin{array}{c}\text { Soma dos } \\
\text { Quadrados }\end{array}$ & df & $\begin{array}{l}\text { Média dos } \\
\text { Quadrados }\end{array}$ & $\mathbf{F}$ & Sig. \\
\hline ET & 1 & $\begin{array}{l}\text { Regressão } \\
\text { Resíduos } \\
\text { Total }\end{array}$ & $\begin{array}{r}1.958 .189,1752 \\
31.963 .538,7983 \\
33.921 .727,9736\end{array}$ & $\begin{array}{r}1 \\
3970 \\
3971\end{array}$ & $\begin{array}{r}1.958 .189,1752 \\
8.051,2692\end{array}$ & 243,215 &, $000 b$ \\
\hline$\overline{\mathrm{ECP}}$ & 6 & $\begin{array}{l}\text { Regressão } \\
\text { Resíduos } \\
\text { Total }\end{array}$ & $\begin{array}{r}24,2179 \\
198,6547 \\
222,8726\end{array}$ & $\begin{array}{r}6 \\
3964 \\
3970\end{array}$ & $\begin{array}{l}4,0363 \\
0,0501\end{array}$ & 80,5416 &, $000 \mathrm{~g}$ \\
\hline ELP & 3 & $\begin{array}{l}\text { Regressão } \\
\text { Resíduos } \\
\text { Total } \\
\end{array}$ & $\begin{array}{r}20,4088 \\
254,6259 \\
275,0348 \\
\end{array}$ & $\begin{array}{r}3 \\
3952 \\
3955 \\
\end{array}$ & $\begin{array}{l}6,8029 \\
0,0644\end{array}$ & 105,587 &, $000 \mathrm{~d}$ \\
\hline ECPF & 4 & $\begin{array}{l}\text { Regressão } \\
\text { Resíduos } \\
\text { Total } \\
\end{array}$ & $\begin{array}{r}4,6861 \\
39,1908 \\
43,8769 \\
\end{array}$ & $\begin{array}{r}4 \\
3966 \\
3970 \\
\end{array}$ & $\begin{array}{l}1,1715 \\
0,0099\end{array}$ & 118,555 &, $000 \mathrm{e}$ \\
\hline ELPF & & $\begin{array}{l}\text { Regressão } \\
\text { Resíduos } \\
\text { Total }\end{array}$ & $\begin{array}{r}4,2247 \\
106,9214 \\
111,1461\end{array}$ & $\begin{array}{r}4 \\
3966 \\
3970\end{array}$ & $\begin{array}{l}1,0562 \\
0,0270\end{array}$ & 39,1763 &, $000 \mathrm{e}$ \\
\hline
\end{tabular}

Fonte: Dados da pesquisa

A Tabela 3 nos evidencia que todas as regressões múltiplas lineares realizadas com as variáveis dependentes ET, ECP, ELP e ECPF são significativas, pois é menor que a significância, rejeitando a hipótese de que $\mathrm{R}^{2}$ é igual a zero.

Isso quer dizer que pelo menos uma das variáveis independentes exerce influência sobre cada variável dependente promovida em cada modelo de regressão. Sendo assim, todos os modelos são significativos para explicar cada variável dependente.
Relacionando a Tabela 2 e a 3 é possível constatar que as regressões são significativas e que seus poderes explicativos, analisados pelos $\mathrm{R}^{2}$ ajustados, percebe-se que é possível levar adiante a análise de cada regressão proposta.

A exceção fica por conta do modelo relacionado à variável ELPF, que possui somente 0,0370 de poder explicativo.

A partir de então foi analisado os resultados dos coeficientes de cada modelo na Tabela 4. 
Determinantes da Estrutura de Capital de Empresas Brasileiras: Uma Análise Empírica das Teorias de Pecking Order e Trade-Off no Período de 2005 e 2014

Tabela 4 - Resultados dos coeficientes de cada regressão múltipla linear

\begin{tabular}{|c|c|c|c|c|c|}
\hline \multirow{2}{*}{$\begin{array}{c}\text { Variáveis } \\
\text { Dependentes }\end{array}$} & \multirow{2}{*}{\multicolumn{2}{|c|}{ Modelos* }} & $\begin{array}{c}\text { Coeficientes } \\
\text { Padronizados } \\
\end{array}$ & \multirow[t]{2}{*}{$\mathbf{t}$} & \multirow[t]{2}{*}{ Sig. } \\
\hline & & & Beta & & \\
\hline \multirow{2}{*}{ ET } & 1 & (Constant) & & 5,874 & ,000 \\
\hline & & ROA &,- 240 & $-15,595$ &, 000 \\
\hline \multirow{7}{*}{ ECP } & 6 & (Constant) & & 34,571 & ,000 \\
\hline & & ROA &,- 202 & $-13,385$ &, 000 \\
\hline & & LC &,- 172 & $-11,185$ & ,000 \\
\hline & & TANG & ,142 & 9,239 &, 000 \\
\hline & & NPGIR & ,038 & 2,517 & ,012 \\
\hline & & CRESCAT &,- 088 & $-2,957$ &, 003 \\
\hline & & CRESCVD & ,061 & 2,055 &, 040 \\
\hline \multirow{4}{*}{ ELP } & 3 & (Constant) & & 35,744 &, 000 \\
\hline & & LC &,- 159 & $-10,180$ &, 000 \\
\hline & & ROA &,- 161 & $-10,491$ &, 000 \\
\hline & & TANG & ,113 & 7,239 &, 000 \\
\hline \multirow{5}{*}{ ECPF } & 4 & (Constant) & & 31,948 & ,000 \\
\hline & & ROA &,- 211 & $-14,023$ &, 000 \\
\hline & & LC &,- 190 & $-12,367$ &, 000 \\
\hline & & TANG & 086 & 5,546 &, 000 \\
\hline & & CRESCAT &,- 074 & $-4,897$ &, 000 \\
\hline \multirow{5}{*}{ ELPF } & 4 & (Constant) & & 24,922 &, 000 \\
\hline & & ROA &,- 119 & $-7,614$ &, 000 \\
\hline & & TANG & , 101 & 6,302 &, 000 \\
\hline & & LC &,- 084 & $-5,269$ &, 000 \\
\hline & & CRESCAT &,- 032 & $-2,008$ &, 045 \\
\hline
\end{tabular}

* significativo ao nível de 5\%.

Fonte: Dados da pesquisa.

Para a regressão na qual envolveu a variável ET, com poder explicativo de $5,75 \%$ (Tabela 2), notase que a variável independente ROA é significativa. Com isso, é possível dizer que o Endividamento Total das empresas analisadas são explicadas por meio do Retornos sobre os Ativos de maneira negativa $(-0,240)$. As variáveis independentes de LC, TANG, ROE, NPGIR, CRESCVD e CRESCAT não entraram no modelo, não possuindo um nível significativo de 5\% para poder explicar o Endividamento Total (Tabela 4).

A regressão proposta com ECP apresentou que ROA, LC, TANG, NPGIR, CRESCAT e CRESCVD forma significativas para explicar a variável dependente ao nível de 5\% (Tabela 4). Reconhece-se que ROA, LC e CRESCAT (respectivamente -0,202; 0,172 e $-0,088$ ) possuem valores negativos e, em contrapartida, as variáveis independentes NPGIR e CRESCVD (respectivamente 0,142 e 0,061 ) explicam de maneira positiva a variável dependente. Seu poder explicativo é de 10,73\% (Tabela 2). Foi a regressão que mais manteve variáveis independentes no modelo (Tabela 4). É possível destacar que as variáveis NPGIR e CRESCVD tiveram como significância os valores percentuais de 1,2 e 4 , ao nível máximo proposto para o modelo de $5 \%$.

A variável ELP, como variável dependente, manteve em seu modelo as variáveis LC, ROA e TANG, com coeficientes negativos para os dois primeiros $(-0,159$ e $-0,161)$ e positivo para TANG, com 0,113 (Tabela 2). Estes são resultados são significativos (Tabela 4) e descrevem que Liquidez Corrente (LC) e Retorno sobre os Ativos (ROA) conseguem explicar a variável Endividamento a Longo Prazo de com seus resultados negativos; já o inverso acontece com a variável explicativa que trata de Tangibilidade.

ECPF como variável dependente, ao modelo que foi apresentado, conseguiu como variáveis 
explicativas ROA (-,0211), LC (-0,190) e CRESCAT ($0,74)$ expressando variáveis com coeficientes negativos (Tabela 4). A variável independente TANG possuiu o resultado de seu coeficiente de 0,86. Todas variáveis independentes expostas ao momento são significativas (Tabela 4).

Como último modelo de regressão linear múltipla, àquela que tratou de demonstrar as variáveis explicativas à variável ELPF foram as mesmas que o modelo anterior, mas, com a seguinte ordem $\mathrm{e}$ resultados: ROA $(-0,119)$; TANG $(0,101)$; LC $(-0,84)$ e CRESCAT $(-0,32)$. Dentro do nível de significância de $5 \%$ todas estas foram incluídas, havendo destaque para a variável independente CRESCAT que obteve 4,5\% de significância.

É de se reconhecer que a regressão que estimam coeficientes de variáveis independentes e, por meio do teste de significância, é possível avaliar o quanto cada fator determinante pode ter como relação às variáveis dependentes de endividamento, estudadas nesta pesquisa.

Estes coeficientes variam entre negativos e positivos, ou seja, essa relação é medida de maneira a significar que a variável independente poderá ter relação positiva ou negativa à variável dependente, estimando alguma explicação como fator determinante ao endividamento das organizações.

\subsection{Comparação dos Resultados Alcançados}

Como já foi mencionado, encontrar um discernimento teórico único para os determinantes da estrutura de capital quanto aos seus relacionamentos com o endividamento não é uma tarefa fácil.

No Quadro 3, percebe-se que as variáveis independentes escolhidas e analisadas neste estudo possuem variações conforme o ponte de vista das teorias, em foco, Pecking Order e Trade Off.

\begin{tabular}{|c|c|c|c|}
\hline & \multirow{2}{*}{ FATORES DETERMINANTES } & \multicolumn{2}{|c|}{ RELAÇÃ̃ ESPERADA } \\
\hline & & TOT & POT \\
\hline $\mathrm{LC}$ & Liquidez Corrente & Não há & Negativa \\
\hline TANG & Tangibilidade do Ativo & Positiva & Positiva \\
\hline $\mathrm{ROA}$ & Retorno sobre os Ativos & Positiva & Negativa \\
\hline ROE & Retorno aos Investidores & Positiva & Negativa \\
\hline NPGIR & Nível de Pagamento do Imposto de Renda & Positiva & Não há \\
\hline CRESCVD & Crescimento das Vendas & Negativa & Positiva/Negativa \\
\hline CRESCAT & Crescimento do Ativo & Positiva & Negativa \\
\hline
\end{tabular}

Quadro 3 - Relação esperada pelas TOT e POT

Fonte: adaptado de Bastos e Nakamura (2009).

Conforme o Quadro 3, percebe-se distinções entre as teorias trade-off e pecking order. No estudo realizado por Nakamura e Bastos (2009), percebe-se que a "liquidez corrente" não foi testada junto à teoria de trade-off, o mesmo acontecendo com a variável "nível de pagamento do imposto de renda" para a teoria de pecking order.

A relação com o endividamento na teoria de trade-off para as variáveis "tangibilidade", "retorno do ativo", "retorno aos investidores", do "nível de pagamento do imposto de renda" e do "crescimento do ativo" é positiva.
Por sua vez, a "liquidez corrente", na teoria de pecking order, possui uma relação negativa com o endividamento. Já a variável "crescimento de vendas" obteve uma relação negativa com o endividamento quando avaliada do ponto de vista da teoria de tradeoff.

No Quadro 4 é demonstrado os resultados do presente estudo a partir dos indicadores de endividamento propostos e fatores determinantes alicerçados teoricamente por estudos anteriores.

\begin{tabular}{|l|l|c|c|c|c|c|}
\hline \multicolumn{2}{|c}{ FATORES DETERMINANTES (*) } & ET & ECP & ELP & ECPF & ELPF \\
\hline LC & Liquidez corrente & Negativa & Negativa & Negativa & Negativa & Negativa \\
\hline TANG & Tangibilidade do ativo & $X$ & Positiva & Positiva & Positiva & Positiva \\
\hline ROA & Retorno sobre os ativos & $X$ & Negativa & Negativa & Negativa & Negativa \\
\hline ROE & Retorno aos investidores & $X$ & $X$ & $X$ & $X$ & $X$ \\
\hline NPGIR & Nível de pagamento de IR & $X$ & Positiva & $X$ & $X$ & $X$ \\
\hline CRESCVD & Crescimento de vendas & $X$ & Negativa & $X$ & $X$ & X \\
\hline CRESCAT & Crescimento do ativo & $X$ & Positiva & $X$ & Negativa & Negativa \\
\hline
\end{tabular}

Quadro 4 - Relação encontrada entre os determinantes e os endividamentos

* (X ) Relação inexistente.

Fonte: Dados da pesquisa. 
A Tabela 5 demonstra de maneira resumida as relações, positivas ou negativas, entre as variáveis explicativas (variáveis dependentes, determinantes ao endividamento das organizações) e as variáveis dependentes (que tratam de endividamento).

Nota-se que as variáveis "tangibilidade do ativo" e "retorno sobre os ativos" estão presentes em quatro tipos de endividamento com os mesmos sinais: de curto prazo; de longo prazo; de curto prazo financeiro; e, de longo prazo financeiro. A primeira variável (TANG) confere a relação esperada com a TOT e inversa com a POT; já a segunda variável tem o mesmo resultado com a POT e inversa com a TOT. Respondente a hipótese 5, realmente, a "tangibilidade dos ativos" é relacionada de maneira positiva com os indicadores de endividamento. Quanto ao "ROA", a relação é negativa para com os indicadores de endividamento, confirmando a hipótese 2 .

Também é possível observar que a variável explicativa "liquidez corrente" se encontra em todos os endividamentos das organizações, inclusive no "endividamento total" sempre de maneira negativa, confirmando o proposto como hipótese 6 .

A variável explicativa "retorno aos investidores" não entrou em nenhuma regressão múltipla linear, demonstrando não haver relação com nenhum endividamento. Portanto, para este estudo, não foi possível comprovar se existe uma relação negativa entre o retorno dos acionistas com os indicadores de endividamento, conforme a hipótese 1 .

Por outro prisma, a variável dependente que mais demonstrou variáveis explicativas foi $o$ "endividamento a curto prazo", com seis das sete variáveis disponibilizadas para testar o modelo.

Já o "endividamento total" foi o inverso, demonstrando somente que a "liquidez corrente" possui algum tipo de relação, mesmo que negativa.

O "crescimento do ativo" obteve três tipos de resultados: para o "endividamento de curto prazo", sua relação acabou sendo positiva, indo ao encontro da TOT e ao encontro da hipótese 3; quando se trata de "endividamentos de curto e longo prazos financeiros onerosos", sua relação acabou sendo negativa, contrariando a hipótese 3 e ao encontro da POT.

Quanto à variável explicativa "crescimento das vendas", sua relação é negativa junto ao "endividamento de curto prazo", sendo coerente com as teorias estudadas (TOT e POT). Isso não foi possível confirmar com os outros níveis de endividamento.

A variável independente "NPGIR" apresentou explicação junto ao "endividamento de curto prazo" de maneira positiva, contrariando a TOT e não indo ao encontro da hipótese 7 , haja vista que não houve possibilidade de comparar com outros níveis de endividamento e pela POT, cuja relação é inexistente.

As limitações deste estudo devem ser comentadas com o intuito de auxiliar em futura $\mathrm{s}$ pesquisas. Para esta, uma das limitações foi quanto à técnica utilizada, a de regressão múltipla linear, na qual houve a preocupação no atendimento dos pressupostos para validação dos resultados dessas regressões.

Outra limitação se dá à tempestividade dos dados. Para estudos com dados de empresas brasileiras, o período de cinco a dez anos é interessante, pois, existem problemas exógenos de âmbito econômico como inflação, moeda, normas contábil-financeiras que não viabiliza uma comparação mais consistente.

Como sugestão para futuras pesquisas seria interessante, por exemplo, a inclusão de mais variáveis dependentes (níveis de endividamento) com valores de mercado. Acredita-se também que outras variáveis com sentido semelhantes poderiam ser testadas, como por exemplo, variáveis de rentabilidade, crescimento, situação tributária, formas diferentes de tamanho de empresa, idade, entre outras.

\section{CONSIDERAÇÕES FINAIS}

O presente trabalho teve como proposta inicial verificar a relação existente entre os determinantes da estrutura de capital e seus respectivos níveis de endividamento, além de comparar os resultados com as teorias de pecking order (POT) e trade off (TOT).

Com isso, foi possível encontrar se os determinantes da estrutura de capital, como variáveis independentes e, por conseguinte, variáveis explicativas, tinham alguma relação, positiva ou negativa, com os níveis de endividamento das organizações analisados no período entre janeiro de 2005 e dezembro de 2014.

Para execução da análise de regressão linear múltipla, foram realizados testes para validação dos pressupostos necessários como de multicolinearidade, autocorrelação residual, homocedasticidade e normalidade dos resíduos.

$\mathrm{O}$ estudo encontrou relações positivas em "tangibilidade dos ativos" e negativa para os "retornos dos ativos", confirmando as respectivas hipóteses. Quando comparadas às teorias de pecking order e trade off, a tangibilidade confirma a relação esperada pela TOT e o retorno sobre os ativos confirma a relação esperada pela POT.

Os resultados de pesquisa encontraram uma "liquidez corrente" que confirma o ponto de vista da POT e a hipótese deste estudo, sendo relacionada negativamente com os indicadores de endividamento.

Já o "retorno aos investidores" não foi possível confirmar a hipótese proposta e, tão pouco, junto às teorias estudadas.

Quanto ao "crescimento dos ativos", os achados foram os seguintes: é a favor da hipótese proposta quando é relacionada positivamente com o "endividamento a curto prazo", cujo resultado vai ao encontro da TOT; diferentemente de quando é relacionada com os "endividamentos de curto e longo 
prazos financeiros onerosos". Neste último caso, ao comparar com as teorias, percebe-se que o resultado corrobora com a expectativa de sinal quando se trata da POT.

Negativamente e a favor da hipótese proposta, a variável "crescimento das vendas" foi ao encontro das teorias estudadas quanto ao endividamento das organizações, ou seja, enquanto na TOT se mantém o sinal negativo, na POT, embora tenha resultado um valor negativo, tem pesquisas que obtém resultados sejam positivos como negativos.

A hipótese 7 foi contrariada quando o "nível de pagamento de imposto de renda" apresentou uma relação positiva junto ao "endividamento de curto prazo", não sendo possível compará-la com outros níveis de endividamento. Este resultado promove a TOT, haja vista que a POT não há nenhuma relação de sinal.

\section{REFERÊNCIAS}

Albuquerque, A. A. (2013). Alavancagem financeira e investimento: um estudo nas empresas brasileiras não financeiras de capital aberto. Tese de Doutorado, Faculdade de Economia, Administração e Contabilidade de Ribeirão Preto, Universidade de São Paulo, Ribeirão Preto. Recuperado em 28 janeiro, 2015, de http://www.teses.usp.br/teses/disponiveis/96/96132/ tde-28032013-100346/

Bastos, D. D. \& Nakamura, W. T. (2009). Determinantes da estrutura de capital das companhias abertas no Brasil, México e Chile no período de 2001-2005. Revista Contabilidade \& Finanças, USP, São Paulo, 20(50), 75-94.

Booth, L., et al. (2001). Capital structures in developing countries. The Journal of Finance, 56, 87-130.

Bradley, M.; Jarrell, G. A.; Kim, E. H. (1984). On the Existence of an Optimal Capital Structure: Theory and Evidence. The Journal of Finance, 39, (3),857878.

Brealey, R.A., Stewart, C., Allen, F. (2010). Principles of corporate finance. 10th ed. New York: McGrawHill Irwin.

Brito, G., Corrar, L., Batistella, F. (2007). Fatores determinantes da Estrutura de Capital das maiores empresas que atuam no Brasil. Revista de Contabilidade e Finanças da USP, São Paulo, (43), 9-19.

Camilo, S. P., Xavier, W. G., De Mello, R. B., \& Marcon, R. (2010). A estrutura de capital como recurso e o efeito no desempenho das firmas. Revista Ibero-Americana de Estratégia, 9 (1), 102126. Recuperado em 28 de janeiro, 2015, de http://dx. doi. org/10.5585/riae. v9i1. 1661

Campos, A. L. S. \& Nakamura, W. T. (2015). Rebalanceamento da estrutura de capital: endividamento setorial e folga financeira. Rio de Janeiro. Revista de Administração Contemporânea, 19, (edição especial), 20-37. Recuperado em 28 de janeiro, 2015, de http://dx.doi.org/10.1590/19827849 rac20151789

Choi, D. Y., Saito, R., \& Silva, V. A. B. (2015). Estrutura de capital e remuneração dos funcionários: Evidência empírica no Brasil/Capital structure and staff salary: empirical evidence in brazil. Revista de Administração Contemporânea, 19(2), 249-269. Recuperado em 26 março, 2018, de http://search.proquest.com/docview/1663521643?ac countid=43603

Corrar, L. J., Paulo, E., Dias Filho, J. M. (2007). Análise Multivariada: para cursos de administração, ciências contábeis e economia. São Paulo: Atlas/FIPECAFI.

Correa, C. A., Basso, L. F. C., Nakamura,W. T. (2013). A estrutura de capital das maiores empresas brasileiras: análise empírica das teorias de Pecking Order e trade-off, usando panel data. Revista de Administração do Mackenzie (online), 14(4), 106133, ISSN 1678-6971. Recuperado em 24 de janeiro, 2015 de http://dx.doi.org/10.1590/S167869712013000400005

Damodaran, A. (2007). Avaliação de empresas. 2. ed. São Paulo: Pearson Prentice Hall.

Eid, JR., W. (1996). Custo e estrutura de capital: o comportamento das empresas brasileiras. Revista de Administração de Empresas, 36(4).

Fama, E. F., French, K. R. (2002). The equity premium. Journal of Finance, 57: (2), 637-659. Recuperado em 20 de janeiro, 2015 de http://links.jstor.org/sici?sici=0022$1082 \% 28200204 \% 2957 \% 3$ A2\%3C637\%3ATEP \%3E2.0.CO\%3B2-\%23

Gomes, G. L., Leal, R.P.C. (2001). Determinantes da estrutura de capitais das empresas brasileiras com ações negociadas em bolsas de valores. IN: LEAL, Ricardo P.C. et al. Finanças Corporativas. Coleção Coppead de Administração. São Paulo: Atlas.

Hovakimian, A., Opler, T., Titman, S. (2001). The debt equity choice. Journal of Financial and Quantitative Analysis, 36(1),1. 
Kayo, E.K., Famá, R. (1997). Teoria de agência e crescimento: evidências empíricas dos efeitos positivos e negativos do endividamento. Caderno de Pesquisa em Administração, 2(5), 1-8.

Kochhar, R. (1997). Strategic assets, capital structure, and firm performance. Journal of Financial and Strategic Decisions, 10(3). Recuperado em 21 de janeiro, 2015 de: http://www.financialdecisionsonline.org/archive/pd ffiles/v10n3/kochhar.pdf

Modigliani, F.; Miller, M. H. (1958). The Cost of Capital, Corporate Finance, and the Theory of Investment. American Economic Review, 48(4), 261-297.

Myers, S. (1984). The capital structure puzzle. The Journal of Finance, 39(3), 575-592.

Myers, S.C, Majluf, N. (1984). Corporate financing and investment decisions when firms have information that investidors do not have. Journal of Financial Economics, 13(2), 187-221.

Nakamura, W. T., Martin, D. M. L., Kayo, E. K. (2004). Proposta para a determinação da estrutura de capital ótima, na prática. Revista de Administração UNISAL, Americana, 1, (1), jul./dez.

Nakamura, W.T., Martin, M.L., Forte, D., Filho, A.F.C., Costa, A.C.F., Amaral, A.C. (2007). Determinantes de estrutura de capital no mercado brasileiro - análise de regressão com painel de dados no período de 1999-2003. Revista Contabilidade \& Finanças , 44, 72 - 85. Recuperado em 26 março, 2018, de www.scielo.br/pdf/rcf/v18n44/a07v1844.pdf
Rajan, R. \& Zingales, L. (1995). What do we know about capital structure? Some evidence from international data. Journal of Finance, 50: 1.4211.460 .

Ross, S. A. (1977). The determination of financial structure: The incentive signalling approach. Bell Journal of Economics, 8: 23-40.

Silveira, A. D. M.; Perobelli, F. F. C.; Barros, L. A. B. de C. (2008). Governança corporativa e os determinantes da estrutura de capital: Evidências empíricas no Brasil/Corporate governance and determinants of capital structure: Empirical evidence from brazilian markets. Revista de Administração Contemporânea, 12(3), 763-788. Recuperado em 28 de janeiro, 2015 http://search.proquest.com/docview/1476893622?ac countid $=43603$

Shyam-Sunder, L. \& Myers, S. (1999). Testing static tradeoff against pecking order models of capital structure. Journal of Financial Economics, 51(2), 219-244.

Sogorb-Mira, F., \& López-Gracia, J. (2002). Pecking order versus trade-off: an empirical approach to the small and medium enterprise capital structure, [Working Paper Series no 393/160], Social Science Eletronic Publishing, Rochester, New York, USA.

Titman, S.; Wessels, R. (1988). The determinants of capital structure choice. Journal of Finance, 48(3).

Vasconcellos, M.A.S. \& Alves, D. (org.) (2000). Manual de econometria. São Paulo: Atlas. 